\title{
HISTÓRIA DA MODA E HISTÓRIADA ARQUITETURA: do frívolo ao efêmero
}

\author{
João Gabriel Farias Barbosa de Araújo \\ Universidade de São Paulo \\ araujojg@usp.br \\ Lara Leite Barbosa \\ Universidade de São Paulo \\ barbosall@usp.br
}

Resumo: O presente artigo trata das aproximações estabelecidas entre o design de moda e a arquitetura, em especial a partir do final do século XIX, situando o leitor sobre o desenvolvimento histórico das relações entre ambas as manifestações culturais. Neste contexto o artigo visa mostrar como se deram esses contatos entre os arquitetos - preocupados com a definição e consolidação de uma estética moderna - e o design de vestuário. A partir da revisão bibliográfica realizada foi possível perceber uma mudança significativa: a moda que antes foi vista, por alguns, como influência negativa hoje é fonte de inspiração para a produção arquitetônica. Tendo em vista que designers e arquitetos dividem técnicas de construção, materiais e vocabulário cada vez mais parecidos, o reconhecimento destas inter-relações é de grande importância. Os trabalhos de artistas, designers e arquitetos contemporâneos demonstram uma evolução destas inter-relações num verdadeiro processo de hibridização.

Palavras-chave: design de moda, história da arquitetura, vestuário, interrelações.

\begin{abstract}
This paper discusses the approaches established between fashion design and architecture, especially from the late nineteenth century, situating the reader about the historical development of relations between the two cultural expressions. In this context, the article aims to show how these contacts took place among architects - concerned with the definition and consolidation of modern aesthetics - and clothing design. From the literature review it was possible to notice a significant change: fashion that was before seen by some as a negative influence today is a source of inspiration for architectural production. Given that designers and architects share construction techniques, materials and increasingly similar vocabulary, the recognition of these interrelations in of great importance.
\end{abstract}


The works of artists, designers and architects show a contemporary evolution of these interrelationships in a genuine process of hybridization.

Keywords: fashion design, history of architecture, clothes, interrelations.

\section{INTRODUÇÃO}

Arquitetura e moda mantêm uma forte relação de proximidade conceitual e prática. Araújo e Miranda (2014) reconhecem que o design de vestuário tem se ocupado de questões antes exclusivas da arquitetura e deixam evidentes as relações entre ambas as manifestações culturais quando analisam os trabalhos de artistas e designers contemporâneos como: Lucy Orta, Do-Ho Suh, CP Company, Vexed Generation e Hussein Chalayan.

$\mathrm{O}$ artigo trata das aproximações estabelecidas entre os arquitetos e o design de vestuário a partir do final do século XIX. É de interesse deste trabalho identificar, e compreender, que tipo de relações foram estabelecidas entre os arquitetos modernos - e seus antecessores - europeus e o vestuário, principalmente o vestuário feminino. A pesquisa tem como uma de suas condições o estudo da moda através da arquitetura, partindo dos escritos e trabalhos de arquitetos.

Leila Kinney (1999) atenta para o fato de que enquanto a moda já foi assunto para extensas pesquisas nas áreas de economia, sociologia e antropologia, poucos escritos sobre o design de moda têm surgido no domínio da arquitetura. Este artigo se consolida, portanto, como uma ferramenta que incentiva o estudo da moda pelo viés da arquitetura.

A partir da revisão bibliográfica realizada foi possível perceber como a moda que antes foi vista, por alguns, como influência negativa hoje é fonte de inspiração para a produção arquitetônica. Os trabalhos de artistas, designers e arquitetos contemporâneos demonstram uma evolução destas inter-relações num verdadeiro processo de hibridização.

Conexões entre as roupas e a arquitetura podem ser percebidas desde a antiguidade, nas primeiras civilizações. Até a mudança da classe dominante, com a ascensão da burguesia, o papel da arquitetura tinha sido de demarcar inquestionáveis diferenças entre a aristocracia e o clero de um lado e os plebeus de outro. As grandes despesas geradas pelas construções demonstravam as diferenças de classes, função muito similar a das roupas da época.

Uma das primeiras relações entre arquitetura, moda e gênero foi feita por Vitrúvio e pode ser encontrada no livro número quatro, de seus dez livros para a arquitetura. Ele associa a coluna dórica com a força e a beleza do corpo masculino, a coríntia representaria o corpo feminino e o luxo enquanto a jônica seria algo entre as duas anteriores, um meio termo.

Para ele [Vitrúvio], o dórico como que exemplifica a 'proporção, força e graça do corpo masculino' - presumivelmente de um homem médio e bemconstituído. O jônico se caracteriza pela 'esbelteza feminina', e o coríntio, por imitar a 'figura delgada de uma menina', o que não difere muito do caso anterior. Uma vez abertas as portas da personalização das ordens, por Vitrúvio, a renascença perdeu o controle, permitindo até interpretações contraditórias. Assim enquanto Scamozzi faz eco a Vitrúvio ao chamar de 
'virginal' a ordem coríntia, Sir Henry Wotton, alguns anos depois, consideraa 'lasciva' e 'ataviada como uma cortesã', não esquecendo de acrescentar que a moral de Corinto era baixa. Seja como for, a ordem coríntia sempre foi vista como feminina e a dórica como masculina, ficando a jônica no meio, como algo assexuado - um velho erudito ou uma matrona calma e gentil (SUMMERSON, 2009, p. 11).

Essa imagem do homem associado à força e a simplicidade da nudez enquanto a mulher é associada com o ornamento e as roupas irá perdurar por muito tempo ressurgindo nos escritos de vários arquitetos modernos como veremos a seguir.

A boa arquitetura, para Vitrúvio, deveria atender a três qualidades: firmitas (sólida), utilitas (funcional) e venustas (bela) e as roupas nunca foram algo realmente sólido, pelo menos não como a arquitetura precisava ser. Para entendermos a "falta de solidez" das roupas em comparação com a arquitetura basta pensarmos na sua matéria-prima principal: o tecido. O tecido representa uma matéria que está entre a solidez das pedras e a fluidez escorregadia dos líquidos, ele é ao mesmo tempo duro e mole, resistente e brando, sólido e fluido (SERRES, 1994).

De fato Vitrúvio não poderia ter feito nenhuma relação entre arquitetura e moda propriamente dita. No século I a.C. ainda não podíamos falar de moda como a conhecemos hoje. Segundo Gilles Lipovetsky (2009, p. 29) ela é "inseparável do nascimento e do desenvolvimento do mundo moderno ocidental", sendo assim o arquiteto romano só poderia chegar à relação entre arquitetura e indumentária.

Visto que só podemos nos referir à moda a partir do surgimento da sociedade moderna, a pesquisa se concentra nas relações entre arquitetura e moda a partir do século $X X$, especialmente nos estudos, tratados e trabalhos de arquitetos europeus que se aventuraram no design de vestuários e/ou que escreveram sobre as associações entre as duas manifestações culturais.

\section{DESENVOLVIMENTO}

A palavra "moda" aparece intermitentemente em escritos sobre arquitetura do final do século XVII até o meio do século XIX, contudo ela não era assunto para extensas investigações. No final do século XIX isso muda substancialmente, a moda se torna tanto uma constante metáfora e um campo de prática para a arquitetura. Gottfried Semper, Sigfried Giedion, Otto Wagner, Adolf Loss e Walter Groupius são alguns daqueles que traçam comparações entre o vestuário e as práticas arquitetônicas, ora denunciando a ornamentação da moda ou exaltando os seus princípios de design. Como metáfora a moda estava quase sempre associada à superficialidade do ornamento, especialmente a moda feminina: frívola e não funcional, representando justamente o oposto da masculina.

Semper entende a "casca" do edifício como um exemplo de "roupa", fazendo associações entre as palavras em alemão wand (parede) e gewand (vestuário). Em "O Estilo" publicado em 1863 são feitas conexões entre arquitetura e roupas, a arquitetura segundo ele teria evoluído das roupas e das tendas ou habitações móveis dos primeiros povos nômades - se opondo à noção de firmitas da boa arquitetura de Vitrúvio. Dessa forma Semper propõe uma origem têxtil da arquitetura, na qual os princípios da construção teriam surgido na tecelagem das primeiras peças do vestuário. $\mathrm{O}$ autor se dedica ao estudo dos tecidos e tramas, pois acreditava que os 
primeiros padrões ornamentais teriam surgido das técnicas e dos materiais utilizados na tecelagem (PAIM, 2000).

É importante notar que as associações feitas por Semper são sempre relacionadas ao vestuário ou aos tecidos. Moda para ele traz junto uma questão mercadológica e está relacionada ao marketing e a rápida circulação de estilos, "resultando em decoração sem personalidade" (FAUSCH et al, 1994, p. 49). Ele deixa o seu legado nos círculos alemão e austríaco - onde as ressonâncias de seus trabalhos eram mais fortes - com o aumento das referências às roupas se tornando comum em escritos sobre arquitetura no final do século XIX.

Quem também estabeleceu paralelos entre a moda e a arquitetura foi Otto Wagner. Diferentemente de Charles Baudelaire - que celebra a aparência feminina e Semper cuja atenção se divide entre a feminina e a masculina - Wagner propõe um modelo de modernidade completamente masculino. Ele aprova a funcionalidade e a honestidade que, segundo ele, são características da moda masculina em comparação com a dissimulação e o ornamento, que para ele seriam próprios da moda feminina.

Características masculinas como rigidez, frieza e transparência são igualmente atribuídas à pedra, ao aço e ao vidro. Para criar um ambiente masculino o uso de ornamentos é reduzido às suas qualidades inerentes e ao mínimo essencial, apoiando-se no lema menos é mais masculino (LICO, 2001, p. 35).

Rejeitando o tipo de ornamentação associado ao vestuário feminino, que segundo ele era algo a ser superado, Adolf Loos defende uma arquitetura baseada na moda masculina, exaltando o terno de alfaiataria como a estética moderna ideal. $\mathrm{Na}$ sua arquitetura está presente a dicotomia interior e exterior, público e privado; para Loos o exterior robusto do edifício deveria ser totalmente diferente do seu interior: "a casa deve parecer reservada por fora, mas por dentro ela deve revelar toda a sua riqueza" (LOOS, 1914, apud FAUSCH et al, p. 64).

Fica claro, em seu ensaio/manifesto "Ornamento e Crime" de 1913, que para Adolf Loss a produção moderna deve rejeitar todo e qualquer tipo de ornamento. 0 arquiteto acredita que o desenvolvimento cultural, artístico e intelectual da sociedade moderna está diretamente relacionado com o abandono da ornamentação. Essa rejeição ao ornamento pode explicar a "fashion fobia" (KINNEY, 1999) de muitos arquitetos modernos, já que a moda feminina sempre esteve diretamente relacionada aos "caprichos" da ornamentação. A moda é vilanizada devido às suas associações com o universo feminino.

Fica evidente a importância do gênero nas relações entre moda e arquitetura. Simioni (2008) denuncia o processo pelo qual as mulheres foram excluídas da Academia Francesa, restando para elas: "as miniaturas, as pinturas em porcelana e as decorativas (vãos, esmaltes etc.), as aquarelas, as naturezas-mortas e [...] particularmente as tapeçarias e bordados" (SIMIONI, 2008, p. 12). Um mecanismo de exclusão semelhante também foi utilizado pala Bauhaus.

Os princípios norteadores revolucionários adotados pela instituição alteraram pouquíssimo as relações entre os gêneros. As mulheres foram sistematicamente desencorajadas a cursar os ateliês mais importantes da escola, como o de arquitetura e pintura, ao passo que o ateliê de 
tecelagem, o menos prestigiado, foi praticamente freqüentado pelo sexo feminino (SIMIONI, 2008, p.14).

A Bauhaus quando elimina o ateliê de design de vestuário e restringe às mulheres os cursos de tecelagem e cerâmica está repetindo os mecanismos de exclusão iniciados com a Academia Francesa. Esse processo só reforça a visão preconceituosa do universo feminino como sendo próprio da ornamentação e futilidade.

\subsection{Modernidade}

Grande parte dos escritos, de arquitetos modernos, que tratavam do diálogo entre moda e arquitetura fazia parte da tentativa de definição e consolidação do que seria a estética moderna. Dois ensaios de autores franceses são importantes na tentativa de definição do que seria a modernidade: "O Pintor da Vida Moderna" de Charles Baudelaire, escrito em 1859-60 e publicado em 1863 no jornal Figaro e os "Tratados da Vida Moderna" de Honoré Balzac, escritos e publicados entre 1830 e 1839 nos jornais La Silhouette, La Mode e L'Europe.

Para Baudelaire a modernidade é o transitório, o efêmero, o contingente. Ele exalta o presente, a mudança, o capricho, o ornamento, o charme e a delicadeza; atributos característicos da relação com o feminino e evitados pela grande maioria dos arquitetos. Os tratados de Balzac, publicados em várias partes, descrevem o comportamento que deve ter o cidadão moderno: como deve se vestir, andar, comer e etc. Balzac acredita que o homem nu é incompleto, o homem na civilização precisa da ajuda do alfaiate para completá-lo, deixando claro que para ele a modernidade se tratava de uma questão exclusivamente masculina. O autor chega, inclusive, a fazer uma comparação entre os elementos da vida elegante e a arquitetura.

Perguntamo-nos, então, se, por acaso, a maioria dos objetos que servem à vida elegante não fazia parte do universo da arquitetura. 0 traje, a cama, o cupê são abrigos da pessoa, como a casa é o grande traje que cobre o homem e as coisas para o seu uso (BALZAC, 2009, p. 71).

No que diz respeito à moda, Baudelaire (1988, p. 202) a considera "uma deformação sublime da natureza, ou melhor, como uma tentativa permanente e sucessiva de correção da natureza", para ele, se trata de um organismo vivificado pelas mulheres uma vez que "tudo que adorna a mulher, tudo que serve para realçar sua beleza, faz parte dela própria” (BAUDELAIRE, 1988, p. 199). Balzac, já acredita que era possível conhecer um homem através da análise de seu vestuário; a moda trabalharia como ferramenta para a estratificação da sociedade, já que, segundo ele, ricos ou pobres estariam apenas preocupados em se distinguir uns dos outros.

Enquanto o primeiro vê na figura do dândi, aquele cuja única profissão é a elegância, cuja única ocupação é cultivar o belo, satisfazer suas paixões, sentir e pensar; o segundo diz que o dândi não passa de um tolo, "um ser pensante... jamais!" (BALZAC, 2009, p. 73), segundo Balzac, para ser elegante era preciso ser um indivíduo dotado de reflexão e inteligência. Baudelaire se defende dizendo:

O dandismo não é sequer, como parecem acreditar muitas pessoas pouco sensatas, um amor desmensurado pela indumentária e pela elegância física. 
Para o perfeito dândi essas coisas são apenas um símbolo da superioridade aristocrática de seu espírito [...] na simplicidade absoluta [...] é, efetivamente, a melhor maneira de se distinguir (BAUDELAIRE, 1988, p. 194).

Para Loos o homem bem vestido é aquele que menos se destaca, enquanto o dândi seria aquele cujas roupas servem para destacá-lo do seu entorno. Loos acredita na anonimidade através das roupas, Le Corbusier também defendia essa mesma anonimidade, no entanto para este ela estava relacionada à padronização e a produção em massa.

Na visão de Le Corbusier o moderno não é nem o exótico nem o passado, está sim representado no colarinho branco e no terno do homem de negócios. Seu desejo é unir a estética pura com a produção em massa. Apesar da relação com a vestimenta masculina, a modernidade de Le Corbusier parece estar relacionada à nudez, para ele, as paredes brancas são um equivalente desta nudez (possivelmente masculina). Outros arquitetos modernos levantaram a relação com a nudez, quase exclusivamente a nudez do homem.

Arquitetos diversos como Walter Groupius, Hugo Häring e George Howe fizeram alusões à moda masculina como modelo de funcionalidade e simplicidade que deveria ser absorvido pela arquitetura.

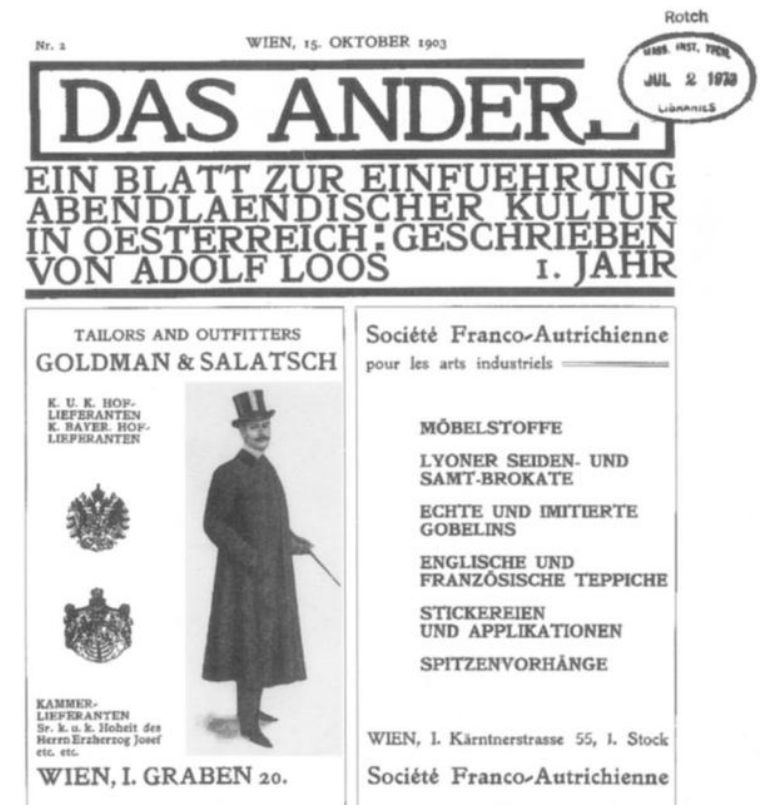

Figura 1 - Capa da revista "Das Andere" №2 contendo um anúncio de uma loja de roupas masculinas com um design de Adolf Loos, 1898.

Fonte: KINNEY, Leila W.. Fashion and Fabrication in Modern Architecture. Journal Of The Society Of Architectural Historians, Oakland, Ca, v. 58, n. 3, p.472-481, set. 1999. Disponível em: <http://www.arch.mcgill.ca/prof/sijpkes/aaresearch-2012/12-studentfiles/architecture-fashion.pdf>. Acesso em: 12 maio 2014.

As questões centrais da arquitetura moderna de: forma segue função, padronização e a máquina como modelo estético encontravam reconhecimento na moda masculina. Ao mesmo tempo em que os arquitetos modernos temiam que sua 
produção fosse associada à feminilidade, rápida obsolescência e ornamento da moda feminina.

Os defensores do modernismo estavam numa batalha para a definição do 'novo' com um adversário poderoso e inevitável; as próprias palavras 'modern', 'moderne' e 'modernité' contêm a raiz 'mode' que precisava ser expurgada (KINNEY, 1999, p.477).

Dois movimentos arquitetônicos escaparam do paradigma do vestuário masculino como um modelo para a modernidade: o futurismo e o construtivismo. No futurismo a constante busca por velocidade e mudança, pode ser relacionada com a moda feminina. Eles denunciam a estaticidade e a brutalidade da moda masculina. Em seu manifesto de 1913 sobre o vestuário masculino, Giacomo Balla defende que as roupas sejam feitas em cores brilhantes e com linhas assimétricas. Ideias que foram colocadas em prática, com a ajuda de sua filha, no ano seguinte.

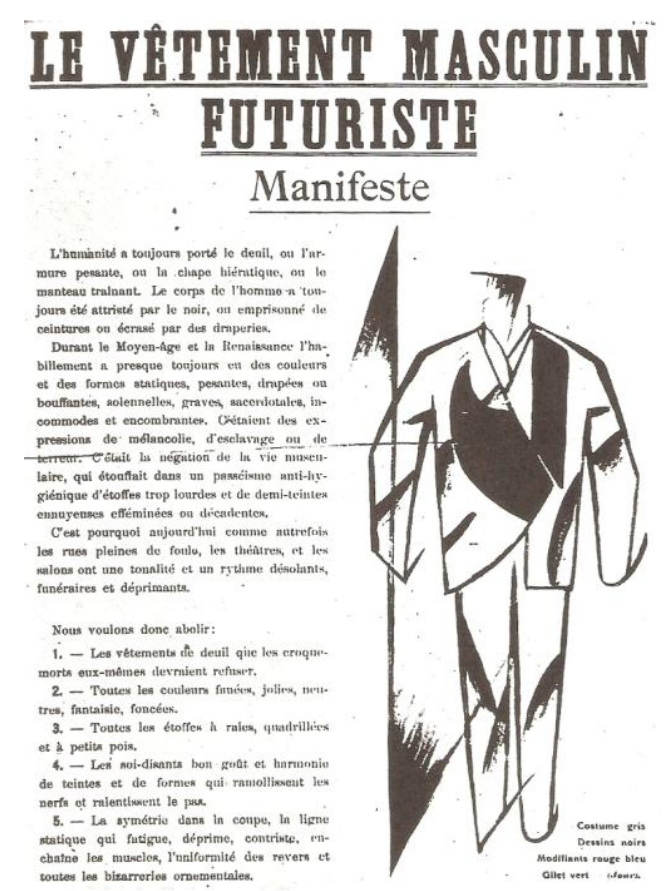

Figura 2 - "O Vestuário Masculino Futurista: Manifesto", Giacomo Balla, Milão, maio de 1914.

Fonte: FAUSCH, Deborah et al. (Org.). Architecture: In Fashion. Nova York: Princeton Architectural Press, 1994.

No construtivismo, designers como Lyubov Popova e Varvara Stepanova veem uma possível reforma do vestuário como parte de uma reforma social que mudaria a relação entre os sexos, a vida doméstica e a divisão de tarefas. Seus designs são ao mesmo tempo funcionais, lúdicos e coloridos; desfazendo distinções de gênero e classe.

\subsection{Reforma do Vestuário Feminino}

No início da década de 1850 um movimento chamado reforma do vestuário defende um modo mais confortável de se vestir. As mulheres queixavam-se do desconforto dos espartilhos, e os reformadores alertavam para o prejuízo físico que 
estas peças causavam. Imbuídas de ideais muito semelhantes, na década de 1880 , mulheres americanas e britânicas se envolvem na busca pelo "vestido prático" (rational dress), tentando abolir os laços apertados, o salto alto e diminuir o peso das peças íntimas.

Por baixo dos ornamentos exteriores que completavam sua toilette, a mulher da moda, no início da década de 1900, era encerrada em várias camadas de roupa de baixo. Vestir-se e despir-se eram tarefas laboriosas, que levavam tempo e exigiam a assistência de uma criada (MENDES; HAYE, 2009, p. 2).

A campanha de reforma do vestuário - que foi ignorada por grande parte dos profissionais da moda desde o seu início até o seu fim, no começo do século XX inspira alguns arquitetos da época a buscar soluções para o guarda-roupa feminino. Peter Behrens, Henry van de Velde, Josef Hoffmann, Richard Riemerschmid, Paul Schultze-Naumburg e Frank Lloyd Wright se envolveram no design de vestuário feminino e viam a moda como um campo de testes na definição do que seria a modernidade em arquitetura. Além de estar diretamente relacionada à definição de uma imagem de modernidade a reforma do vestuário também estava ligada a emancipação feminina e a criação de novos ideais de beleza.

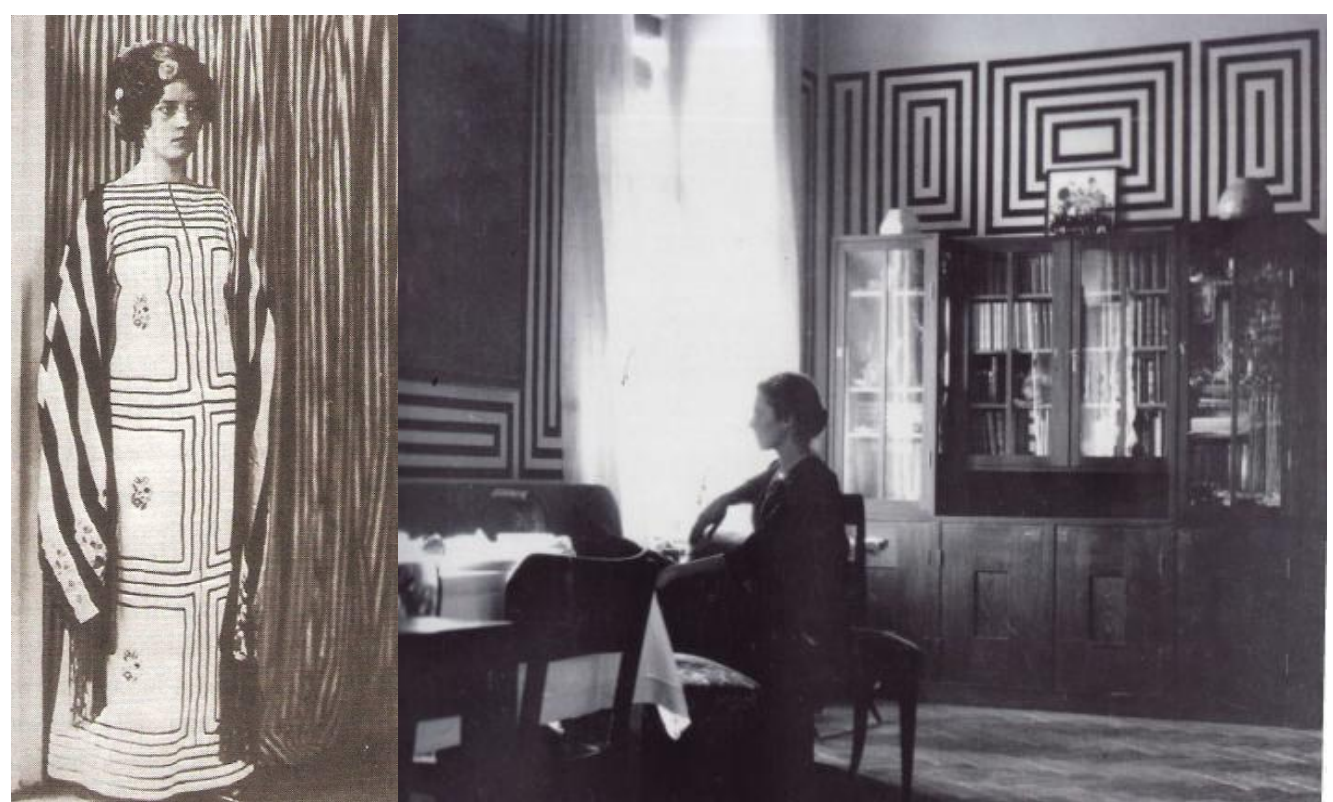

Figura 3 - Esquerda: "Summer Dress" design de Joseph Hoffman, 1901. Direita: Interior projetado por Josef Hoffman.

Fonte: FAUSCH, Deborah et al. (Org.). Architecture: In Fashion. Nova York: Princeton Architectural Press, 1994.

http://aasid.parsons.edu/decorationascomposition/content/josef-hoffmannresidential-interiors acesso em 13 de agosto de 2014.

Todos estavam descontentes com as, então atuais, formas do vestuário feminino e tentaram transformá-lo buscando linhas mais fluidas, no entanto se mostraram mais preocupados em fazer belas roupas inspiradas nos interiores também projetados por eles, criando uma espécie de cenografia para suas construções (KINNEY, 1999). Apesar das altas expectativas depositadas nas peças - que eram 
consideradas por seus criadores como obras de arte e não como moda - uma exposição em Krefeld (1900) causou pouco impacto.

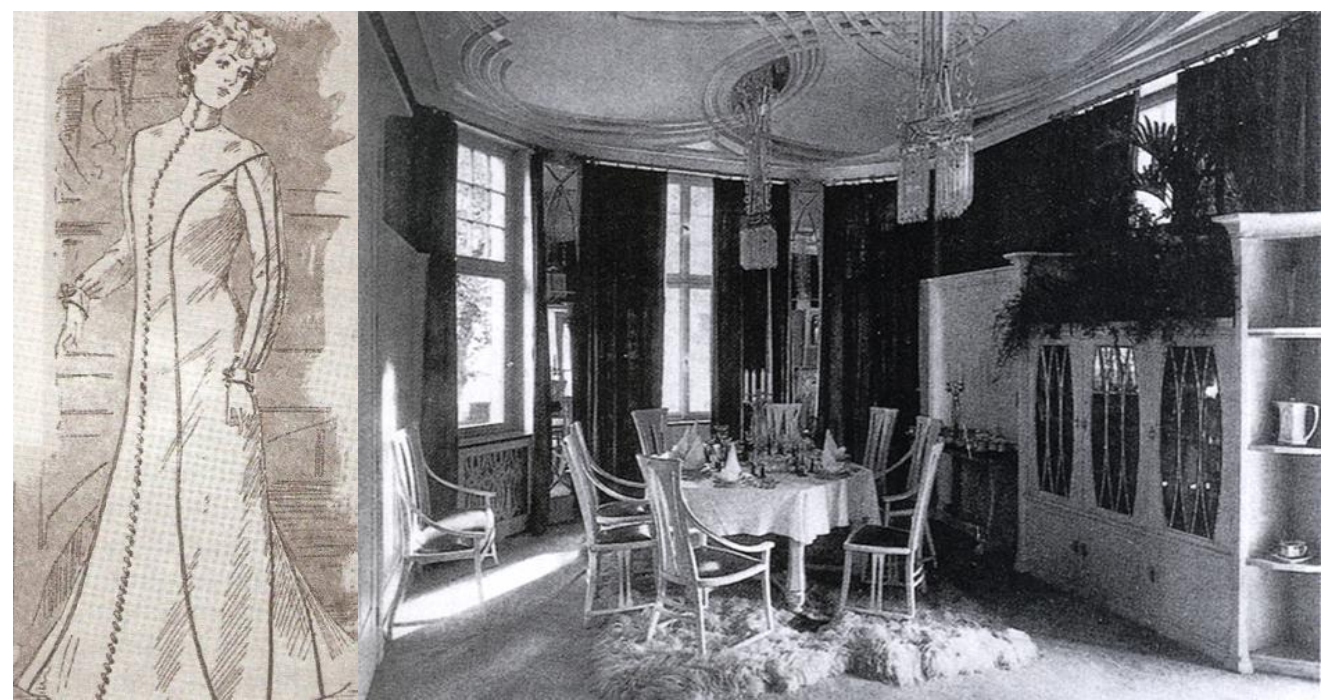

Figura 4 - Esquerda: "House Dress" design de Peter Behrens, 1901. Direita: Interior projetado por Peter Behrens para casa em Darmstadt, 1899.

Fonte: FAUSCH, Deborah et al. (Org.). Architecture: In Fashion. Nova York: Princiton Architectural Press, 1994.

http://www.daniellaondesign.com/blog/peter-behrens-house-in-darmstadt acesso em 13 de agosto de 2014.
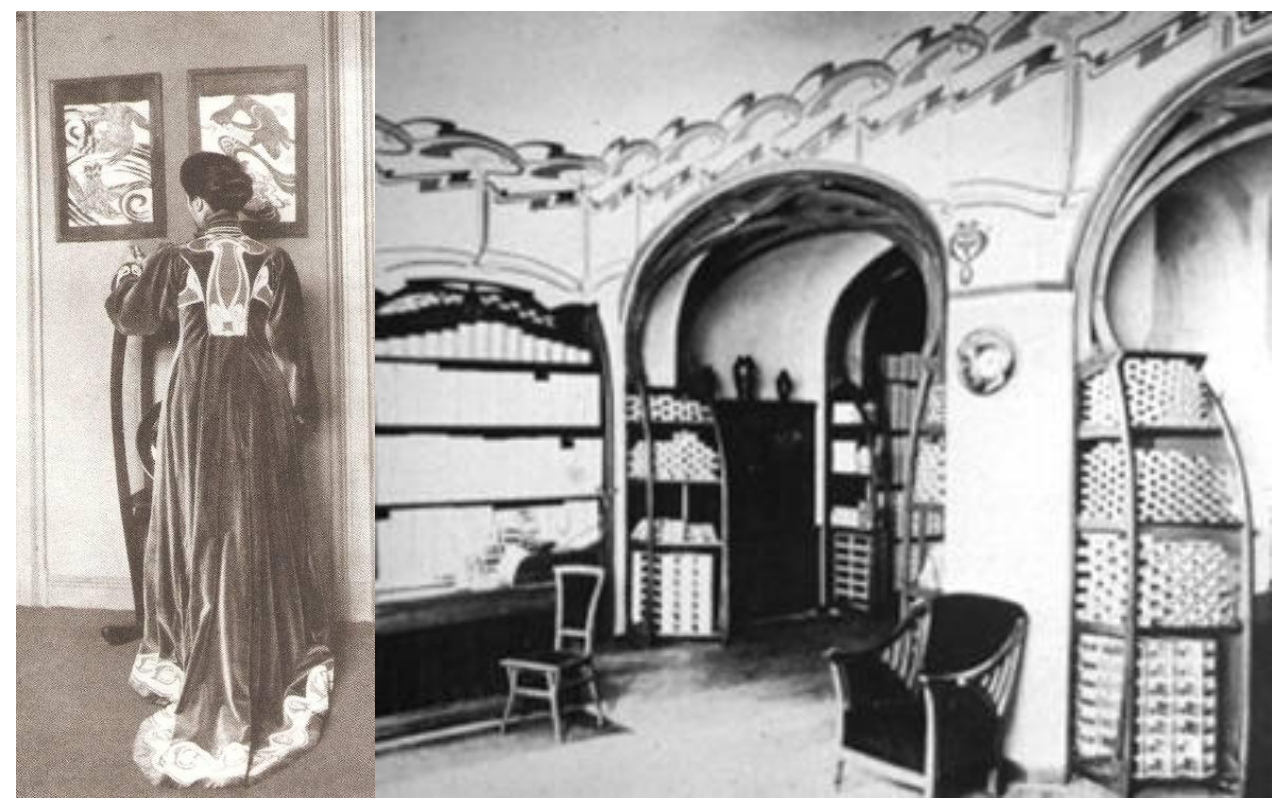

Figura 5 - Esquerda: "House Dress" design de Peter Behrens, 1901. Direita: Interior projetado por Henry van de Velde, 1899-1900.

Fonte: FAUSCH, Deborah et al. (Org.). Architecture: In Fashion. Nova York: Princiton Architectural Press, 1994.

http://volumenarquitectura.blogspot.com.br/ acesso em 13 de agosto de 2014.

As mudanças significativas para a criação de moda começam efetivamente durante a Primeira Guerra Mundial (1914-1918). Em 1916 com o número cada vez maior de homens alistados, as mulheres se tornaram a única força de trabalho o que 
levou ao surgimento de novas abordagens do vestuário de trabalho que inevitavelmente acabaram por influenciar o vestuário social.

Em 1923 as saias ainda eram longas, mas em 1925 a revolução finalmente acontece no vestuário feminino e elas subiram para a altura do joelho. Surge assim uma nova geração de estilistas: Madeleine Vionet, Jeanne Lanvin, Coco Chanel e Elsa Schiaparelli (que se junta ao grupo dois anos depois). As mulheres agora controlavam a moda.

De 1920 a 1925 a moda segue dois cursos: um tradicionalmente feminino e romântico e o novo, mais modernista. O novo visual foi chamado de garçonne, termo que teria saído de uma novela de Victor Margueritte de 1922.

La garçonne [...] conta a história de uma jovem progressista, que deixa a casa da família em busca de uma vida independente. O visual garçonne era antes uma aspiração que uma realidade já que relativamente poucas mulheres realmente experimentavam a liberdade social, econômica e política (MENDES; HAYE, 2009, p. 52).

O estilo garçonne de corte folgado e reto, fácil de fazer e feito de material leve, era ideal para as máquinas de costura domésticas, assim como para a produção em massa além de ser econômico - dois ou três metros de tecido eram suficientes para um vestido. Todas essas características o aproximavam dos ideais da arquitetura moderna apresentada por Le Corbusier, na Exposition Internationale des Arts Décoratifs et Industriels, em Paris (1925). As linhas lisas, angulares e geométricas do arquiteto dominaram a moda e o design têxtil, ou seria o contrário? Difícil saber se a moda estava guiando a arquitetura ou vice e versa. Branco, preto, cinza e bege neutros eram as cores da vanguarda e nas raras ocasiões em que se usavam padrões estes tendiam a ser lineares e geométricos.

Adolf Loos via na emancipação da mulher a abolição de tudo aquilo que era previamente feminino, resultando na erradicação das distinções entre os vestuários masculino e feminino. Em contraste com Baudelaire e Semper ele via uma modernidade puramente funcional, uma modernidade que iria transcender as mudanças frívolas da moda e do gosto feminino.

A modernidade masculina prevista por Loos não se concretiza. No final da década de 1920 a moda feminina já combinava as características do vestuário masculino e feminino: funcionalismo, simplicidade e ao mesmo tempo erotismo e fantasia. As mulheres alcançam uma nova liberdade, mas não se igualando aos homens.

Em 1924, o escritor e historiador Gerald Heard estabeleceu, em seu livro "Narcissus: an anatomy of clothes", duas alternativas para o futuro das roupas e da arquitetura, que ele considerava intimamente ligadas. Primeiro remanescente do futurismo é uma arquitetura mais leve e ao mesmo tempo forte, reciprocamente impondo um vestuário mais limpo, próximo e conveniente. A cor voltaria às superfícies dos edifícios e seu reflexo seria visto nas roupas masculinas. A segunda é que a arquitetura tome o lugar das roupas e outra arte mais austera, menos intima (como a engenharia) tome o lugar da arquitetura. "O arquiteto deve se parecer mais com um alfaiate do que com um construtor. Devemos viver para mudar de edifícios como as mulheres mudam suas roupas" (HEARD, 1924, apud FAUSCH et al., 1994, p. 80). 


\section{CONSIDERAÇÕES FINAIS}

A importância do estudo histórico das relações entre arquitetura e design de vestuário pode ser confirmada através da relação cada vez mais intima que vemos surgir entre a produção de moda e arquitetônica. Esse constante se reflete hoje num processo de "hibridização" nas criações de artistas, designers e arquitetos. A produção contemporânea tem, cada vez mais, dissolvido as fronteiras entre arte, moda e arquitetura, dificultando a tarefa de estabelecer limites entre as diversas manifestações.

Artistas como Lygia Clark, Lygia Pape, Martín Azúa, Andrea Zittel e Hélio Oiticia trabalham com conceitos que fazem parte do repertório da arquitetura e também da moda, corpo, pele, habitação e abrigo são apenas alguns deles. Os trabalhos de designers como Jum Nakao, Hussein Chalayan, Alexander McQueen, Yohji Yamamoto e Issey Miyake apresentam congruências práticas e conceituais estimuladas por avanços na área da arquitetura, entre eles a descoberta de novos materiais e o desenvolvimento de softwares de computação. Os arquitetos Herzog \& de Meuron, Lina Bo Bardi, Jean Nouvel, Rem Koolhaas e Greg Lynn - para citar apenas alguns buscam novas formas para acomodar o corpo e acabam encontrando, consciente ou inconscientemente, no vestuário uma importante fonte de inspiração e de recursos materiais, conceituais e poéticos, já que nossas roupas estão mais próximas do nosso corpo do que qualquer arquitetura. A moda que antes foi vista, por alguns, como influência negativa hoje é parceira da produção arquitetônica.

O monstro da moda, não satisfeito em cravar suas garras na arte e na arquitetura, deu outra bocada e engoliu o design inteiro (SUDJIC, 2010, p. 140).

Vimos como o movimento moderno advogava por uma arquitetura que fosse livre de qualquer tipo de ornamento. Mas mais importante, quando associavam o ornamento e a futilidade à feminilidade não estariam, os arquitetos modernos, defendendo a ideia de que a arquitetura deveria evitar o universo feminino? A política da Bauhaus dificultando o acesso das mulheres aos ateliês de maior estima nos dá um indício que poderia confirmar esta hipótese.

Com os arquitetos anteriores ao movimento da arquitetura moderna - que se envolveram diretamente com o design de moda na tentativa de reforma do vestuário feminino - constatamos como havia pouco interesse na produção de trajes que fossem realmente confortáveis. Quando Joseff Hoffman, Paul Schultze-Naumberg, Peter Behrens e Henry van de Velde desenham vestidos para compor com os interiores de seus projetos é como se estivessem, de certa forma, dizendo que o lugar das mulheres era dentro de casa.

Nenhum dos arquitetos envolvidos com a reforma, sequer, chega a propor o encurtamento das saias, mas percebemos que vinte e cinco anos depois as saias se encurtam. Uma vitória alcançada graças ao trabalho das próprias mulheres. 0 vestuário pode ter sido importante na conquista das mulheres pelo direito de ocupar o seu lugar na sociedade moderna. Entendemos a importância da participação feminina no design, em especial na reforma do traje feminino.

O design de vestuário pode ser um aliado da arquitetura na busca por uma nova forma de projetar com formas mais efêmeras, uma vez que já tem demonstrado diversos sinais de adaptação à nova realidade que estamos vivendo. Os trabalhos de 
CP Company e Vexed Generation redefinem os "limites entre roupa, abrigo, espaço público e urbano através de estruturas que podemos vestir" (ARAÚJO; MIRANDA, 2014 , p. 162) além de discutirem a questão do nomadismo urbano.

A teatralização dos desfiles de moda, as parcerias entre grifes e arquitetos renomados, transformando as lojas em marcos arquitetônicos, e a reinvenção da moda como uma forma de arte através da arquitetura são apenas alguns dos desdobramentos contemporâneos destas inter-relações, que podem e estão sendo abordados em trabalhos futuros. Este trabalho abre espaço para a inclusão da questão do gênero na pesquisa das inter-relações entre design e arquitetura.

\section{REFERÊNCIAS}

ARAÚJO, João Gabriel F. B. de; MIRANDA, Clara Luiza. O espaço da moda: primeira casa ou segunda pele. Revista Ciclos, Florianópolis, v. 1, n. 2, p. 158-173, mar. 2014.

BALZAC, Honoré. Tratados da Vida Moderna. São Paulo: Estação Liberdade, 2009.

BAUDELAIRE, Charles. O Pintor da Vida Moderna. In: COELHO, Teixeira. A Modernidade de Baudelaire. São Paulo: Paz e Terra, 1988. p. 159-212.

FAUSCH, Deborah et al. (Org.). Architecture: In Fashion. Nova York: Princeton Architectural Press, 1994.

KINNEY, Leila W.. Fashion and Fabrication in Modern Architecture. Journal Of The Society Of Architectural Historians, Oakland, Ca, v. 58, n. 3, p.472-481, set. 1999. Disponível em: <http://www.arch.mcgill.ca/prof/sijpkes/aaresearch-2012/12-studentfiles/architecture-fashion.pdf>. Acesso em: 12 maio 2014.

LICO, Gerard Rey. Architecture and Sexuality: The Politics of Gendered Space. Humanities Diliman, Filipinas, v. 2, n. 1, p.30-44, jan. 2001. Disponível em: <http://journals.upd.edu.ph/index.php/humanitiesdiliman/article/view/74/56>.

Acesso em: 14 ago. 2014.

LIPOVETSKY, Gilles. O Império do Efêmero: a moda e seu destino nas sociedades modernas. São Paulo: Companhia de Bolso, 2009.

MENDES, Valerie; HAYE, Amy de la. A Moda do Século XX. 2a ed. São Paulo: Martins Fontes, 2009.

PAIM, Gilberto. A beleza sob suspeita. Rio de Janeiro: Jorge Zahar, 2000.

SERRES, Michel. Atlas. Lisboa: Instituto Piaget, 1994.

SIMIONI, Ana Paula Cavalcanti. Descosturando gêneros: da feminização das artes têxteis às subversões contemporâneas. In: OLIVEIRA, Ana Claudia de; CASTILHO, Kathia (Org.). CORPO E MODA: por uma compreensão do contemporâneo. Barueri: Estação das Letras e Cores, 2008. p. 11-23.

SUDJIC, Deyan. A Linguagem das Coisas. Rio de Janeiro: Intrínseca, 2010.

SUMMERSON, John. A linguagem clássica da arquitetura. 5ạ ed. São Paulo: Martins Fontes, 2009. 